\title{
Automotive Occupations
}

National Cancer Institute

\section{Source}

National Cancer Institute. Automotive Occupations. NCI Thesaurus. Code C103933.

A class of professional or vocational positions of employment that involve work with automobiles. 